\title{
Meta-analysis, validation and application of fruit fly development times
}

\author{
J.M. Kean \\ AgResearch Ltd, Ruakura Research Centre, Private Bag 3123, Hamilton 3240, \\ New Zealand, and Better Border Biosecurity (B3, b3nz.org) \\ Corresponding author: john.kean@agresearch.co.nz
}

\begin{abstract}
Tephritid fruit flies have been comparatively well studied because of the damage they cause to horticultural crops in affected countries. New Zealand benefits from this knowledge as it continues to exclude economically damaging fruit fly species. For example, fruit fly development models are used for biosecurity risk analysis and decision making during incursion responses. Here, the literature was searched for development times for three species of particular concern to New Zealand: the Mediterranean fruit fly, the Queensland fruit fly and the oriental fruit fly. The published data were re-analysed to fit development models to the different life stages and the generation time. The new models were then compared with previously published models for these species. The generation time models were found to give reasonably accurate predictions when validated against published estimates of field voltinism overseas. This paper presents the most comprehensive analysis to date of fruit fly development times and degree day models.
\end{abstract}

Keywords biosecurity, phenology, risk analysis, Tephritidae, voltinism.

\section{INTRODUCTION}

Fruit flies (Diptera:Tephritidae) include some of the most economically significant horticultural pests world-wide. New Zealand is naturally free of damaging fruit flies, and biosecurity authorities implement various systems to prevent introduction and establishment, including surveillance trapping (Acosta \& White 2011). While all exotic tephritids are considered a threat to New Zealand horticulture, three species of particular concern are the Queensland fruit fly (Qfly), Bactrocera tryoni (Froggatt), the Mediterranean fruit fly (Medfly), Ceratitis capitata (Wiedemann) and the oriental fruit fly, Bactrocera dorsalis sensu stricto (Hendel).

Because of their significance to horticulture, fruit flies have been comparatively well studied in infested countries, and New Zealand benefits from this knowledge in its efforts to exclude economically damaging species. For example, there have been many laboratory studies on the development times of fruit flies at different constant temperatures, and publication of a plethora of development models. These models can be useful both for risk analysis and for informing surveillance and eradication programmes (Nietschke et al. 2007), but it is not clear which models are the best nor how much natural variability in development times occurs within species.

Here, previously published data for development times of Qfly, Medfly and oriental fruit fly at constant temperatures 
are re-analysed and used to predict voltinism (number of generations per year) in the field. These predictions are compared to published observations. The use of these models for New Zealand biosecurity is also discussed.

\section{MATERIALS AND METHODS}

Development times at constant temperature were compiled from the literature, and new development models were fitted to the full data set available for each life stage of each species. Development models are usually fitted by least-squares regression as linear relationships between development rate (1/development time) and temperature, but this method may lead to misleading predictions, particularly at low temperatures (Kramer et al. 1991). Instead, non-linear regression (Brown 2001) was used to fit models directly to the data as $d=q$ / $(T-b)$ where $d$ is development time in days, $q$ is the total degree days required to complete development, $T$ is temperature in ${ }^{\circ} \mathrm{C}$ and $b$ is the base temperature below which development ceases. New Zealand is generally cooler than the native ranges of most fruit flies, and this method results in more accurate predictions for lower temperatures (Kramer et al. 1991). Variability was assessed as the $95 \%$ confidence interval around the fitted line, although this will underestimate the variability between individual insects because the data themselves represent the median result from a replicated experimental treatment.

To estimate generation time, the component models for eggs, larvae, pupae and prereproductive females needed to be scaled to a common base temperature $b_{c}$, which was the average of all the stages' $b$ values weighted by their relative durations $q$. Models were refitted to the data as $d=q_{c} /\left(T-b_{c}\right)$ and the resulting $q_{c}$ values for each stage were added to estimate the overall developmental requirement. When raw laboratory data were unavailable, the stage models were re-scaled around a pivot temperature of $25^{\circ} \mathrm{C}$ (close to optimum for many fruit flies) as $q_{c}=q \times\left(25-b_{c}\right) /(25-b)$ (Morris \& Fulton 1970). This rescaling assumes that the original model gave the correct development time at $25^{\circ} \mathrm{C}$ and recalculates the developmental requirement $q_{c}$ from the adjusted base temperature $b_{c}$. This function could also be plotted in $q$ versus $b$ parameter space to indicate approximately equivalent models.

The new models were then validated as follows. Published observations of voltinism (number of generations per year in the field) were compiled, and daily maximum and minimum temperatures were interpolated for these sites from the nearest CliMond site (Kriticos et al. 2012). For each location, the development models were used to predict voltinism from the temperature data using the 4-step method (Kean 2013). Comparison between observed and predicted voltinism indicated how well the laboratorybased development models apply in the field.

\section{RESULTS}

\section{Development models}

Queensland fruit fly

Surprisingly, no systematic experimental study of the development rates of Qfly in relation to temperature has been published. Pritchard $(1970,1978)$ gave data for egg development and the female pre-reproductive period, to which nonlinear models were fitted. Yonow et al. (2004) used these models and all other available data to derive development rates $r$ for each life stage in the linear form $r=m \times T-c$, where $m$ is the linear slope and $c$ the $y$-axis intercept. Here, these parameters were recast using $q=1 / \mathrm{m}$ and $b=c / m$. The Australian code of practice (COP) for management of Queensland fruit fly (Anonymous 1996) uses values from an unpublished model by BS Fletcher of CSIRO, which differ considerably (Figure 1). Given that this model is not documented, Yonow's values were used: eggs require $26.2^{\circ} \mathrm{d}$ above $11.1^{\circ} \mathrm{C}$; larvae $164^{\circ} \mathrm{d}$ above $10.0^{\circ} \mathrm{C}$; pupae $163^{\circ} \mathrm{d}$ above $11.2^{\circ} \mathrm{C}$; and the female pre-reproductive period requires $92.6^{\circ} \mathrm{d}$ above $12.3^{\circ} \mathrm{C}$. Re-scaling to a common base temperature suggested a mean minimum generation time (egg to first egg) of $447^{\circ} \mathrm{d}$ above $11.0^{\circ} \mathrm{C}$. In comparison, Meats (1981) suggested a nonlinear model for egg to first egg that approximates to $481^{\circ} \mathrm{d}$ above 
$10^{\circ} \mathrm{C}$. Mean generation time (egg to median egg) was estimated from life table studies. At $25^{\circ} \mathrm{C}$, Fitt (1990) estimated the mean generation time at 43 days; assuming an $11.0^{\circ} \mathrm{C}$ base temperature, the degree day requirement was $43 \times(25-11)=602^{\circ} \mathrm{d}$.

\section{Mediterranean fruit fly}

Considerably more data were available for Medfly (Figure 2). Egg development times from ten different studies (listed in Figure 2) suggested $37.8 \pm 1.2^{\circ} \mathrm{d}$ were needed above $10.0^{\circ} \mathrm{C}(\mathrm{df}=58$, $\left.\mathrm{R}^{2}=0.978\right)$. Data from ten studies, excluding results from sub-optimal hosts, suggested larvae required $106.6 \pm 4.1^{\circ} \mathrm{d}$ above $10.7^{\circ} \mathrm{C}(\mathrm{df}$ $\left.=39, \mathrm{R}^{2}=0.916\right)$. Similarly, data from eleven studies suggested pupae required $186.2 \pm 3.4^{\circ} \mathrm{d}$ above $9.1^{\circ} \mathrm{C}\left(\mathrm{df}=75, \mathrm{R}^{2}=0.935\right)$. Female pre-

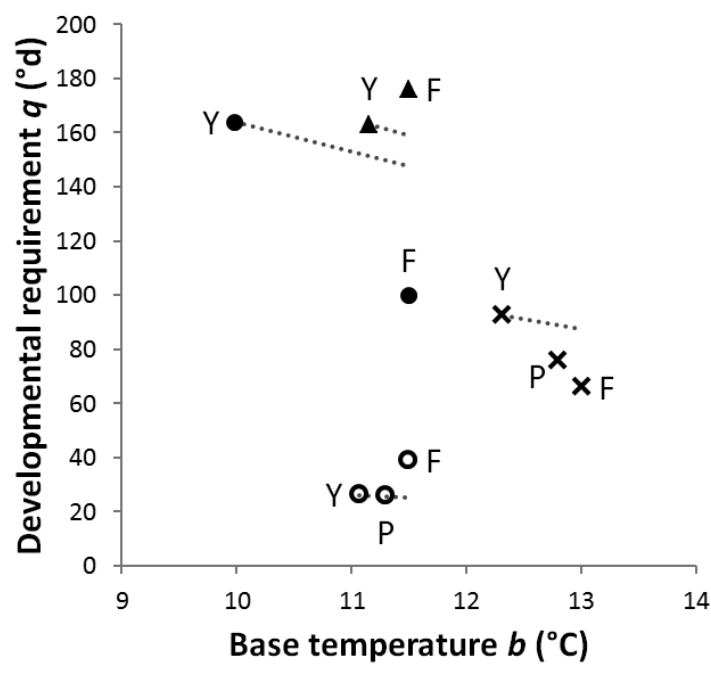

○ Eggs $\bullet$ Larvae $\Delta$ Pupae $\mathbf{x}$ Pre-reproductive females

Figure 1 Comparison of development parameters for Queensland fruit fly life stages. Parameter sources: $\mathrm{P}=$ Pritchard (1970, 1978); $\mathrm{F}=$ Fletcher (cited in Anonymous 1996); $\mathrm{Y}=$ Yonow et al. (2004). Dotted lines show equivalent development requirements estimated using a pivot temperature of $25^{\circ} \mathrm{C}$; models appearing above the line suggest longer development times, those below the line shorter. oviposition times were available from only six studies, and these showed substantial variability. In particular, the values measured from Hawai'ian populations (marked V in Figure 2) were substantially longer than those measured elsewhere. The model fitted in this case was $94.9 \pm 12.6^{\circ} \mathrm{d}$ above $9.5^{\circ} \mathrm{C}(\mathrm{df}=19)$, but this has poor predictive power $\left(\mathrm{R}^{2}=0.424\right)$. Refitting the models with a common base temperature suggested a mean minimum generation time of $41.8+125.5+149.7+92.1=409.1^{\circ} \mathrm{d}$ above $9.7^{\circ} \mathrm{C}$ for egg to first egg. This was comparable to the $391.4 \pm 6.6^{\circ} \mathrm{d}$ above $9.3^{\circ} \mathrm{C}\left(\mathrm{df}=8, \mathrm{R}^{2}=\right.$ 0.982) fitted to egg-to-first-egg development times reported in two studies (Muñiz \& Zalom 1997; Grout \& Stoltz 2007). It was, however, substantially shorter than the mean generation time requirement of $659^{\circ} \mathrm{d}$ above $8.3^{\circ} \mathrm{C}(\mathrm{df}=30$, $\left.\mathrm{R}^{2}=0.890\right)$ fitted to results from five life table studies (Vargas et al. 1984, 1997, 2000; Krainacker et al. 1987; Papadopoulos et al. 2002).

\section{Oriental fruit fly}

Many of the studies of oriental fruit fly development were published in Chinese academic journals with a short English summary. Raw development time data were found in eight papers, and a further four papers published values for $b$ and $q$ in their English abstracts (these are listed in the caption for Figure 3). Models fitted to the raw data (Figure 3 ) suggested egg development requires $26.8 \pm 0.6^{\circ} \mathrm{d}$ above $10.5^{\circ} \mathrm{C}$ $\left(\mathrm{df}=32, \mathrm{R}^{2}=0.986\right)$, larvae require $146.8 \pm 4.0^{\circ} \mathrm{d}$ above $6.9^{\circ} \mathrm{C}\left(\mathrm{df}=18, \mathrm{R}^{2}=0.677\right)$ and pupae need $179.2 \pm 2.3^{\circ} \mathrm{d}$ above $9.2^{\circ} \mathrm{C}\left(\mathrm{df}=18, \mathrm{R}^{2}=0.956\right)$. Few studies reported pre-oviposition times and these were so variable that a fitted model had little predictive power $\left(\mathrm{R}^{2}=0.293\right)$. Without a reliable model for the pre-oviposition period, the minimum egg-to-egg generation time cannot be estimated by summing the requirements of prereproductive stages. However, six life table studies (Vargas et al. 1984, 1997, 2000; Liu et al. 1985; Yang et al. 1994; Zhang et al. 2010) estimated mean generation times at different temperatures, which suggest a requirement of $876 \pm 34^{\circ} \mathrm{d}$ above $9.5^{\circ} \mathrm{C}\left(\mathrm{df}=18, \mathrm{R}^{2}=0.752\right)$. 

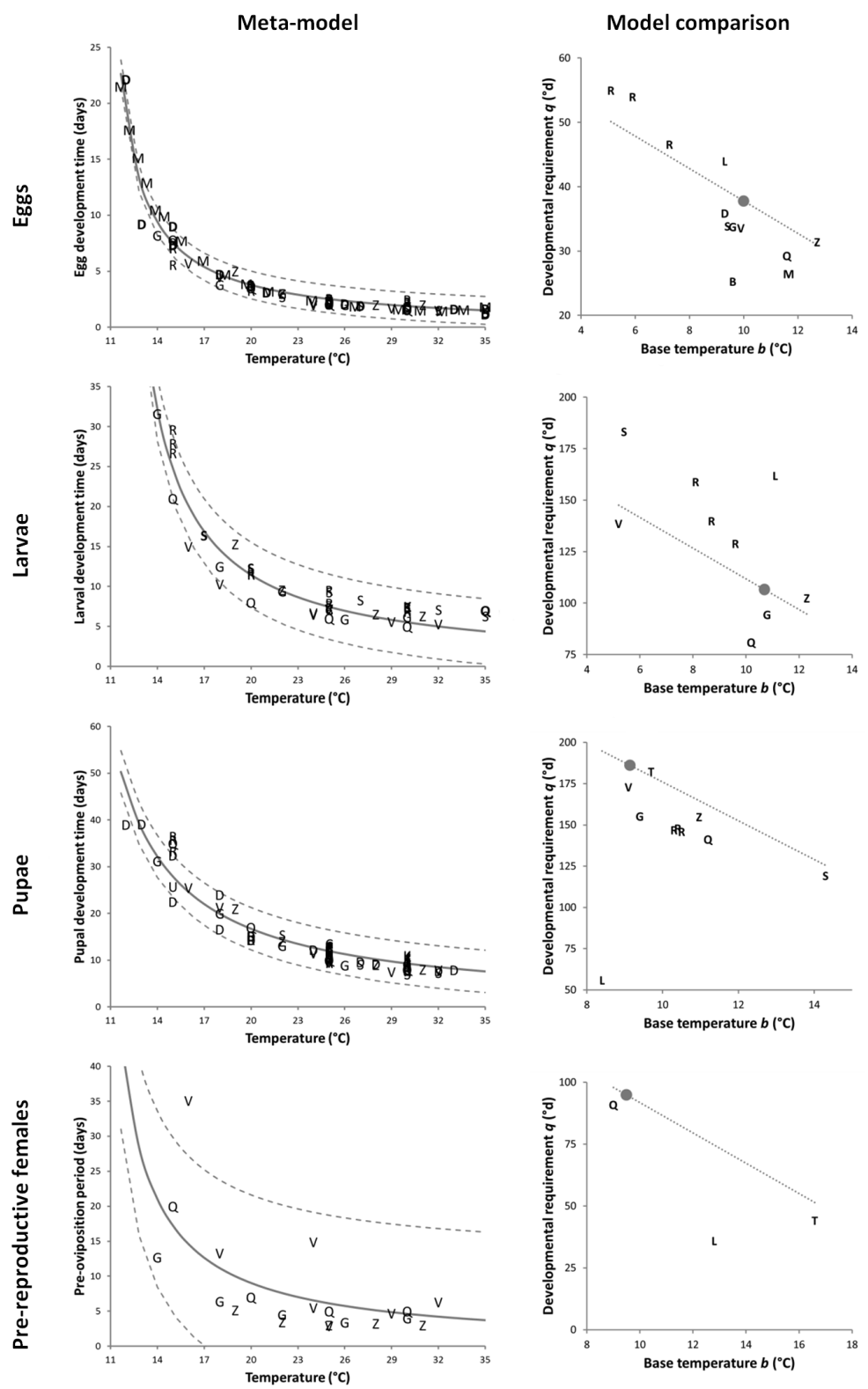

Figure 2 Meta-analysis of development times for Mediterranean fruit fly life stages. Meta-model fits are shown on the left (data, solid line fit and dashed line 95\% confidence range), and compared to other published models on the right. The meta-model is indicated by a dot with dotted lines indicating equivalent requirements around a $25^{\circ} \mathrm{C}$ pivot temperature; models appearing above the line suggest longer development times, those below the line shorter. Data sources: C = Carey (1984); D = Crovetti et al. (1986) and Delrio et al. (1986); G = Grout \& Stoltz (2007); K = Krainacker et al. (1987); L = De Lima (2008); M $=$ Messenger \& Flitters (1958); P = Papadopoulos et al. (2002); Q = Duyck \& Quilici (2002); R = Ricalde et al. (2012); $S$ = Shoukry \& Hafez (1979); $T$ = Tassan et al. (1982) from Bodenheimer (1951); U = QuesadaMoraga et al. (2012); V = Vargas et al. (1984, 1996, 1997, 2000); Z = Muñiz \& Zalom (1997). 

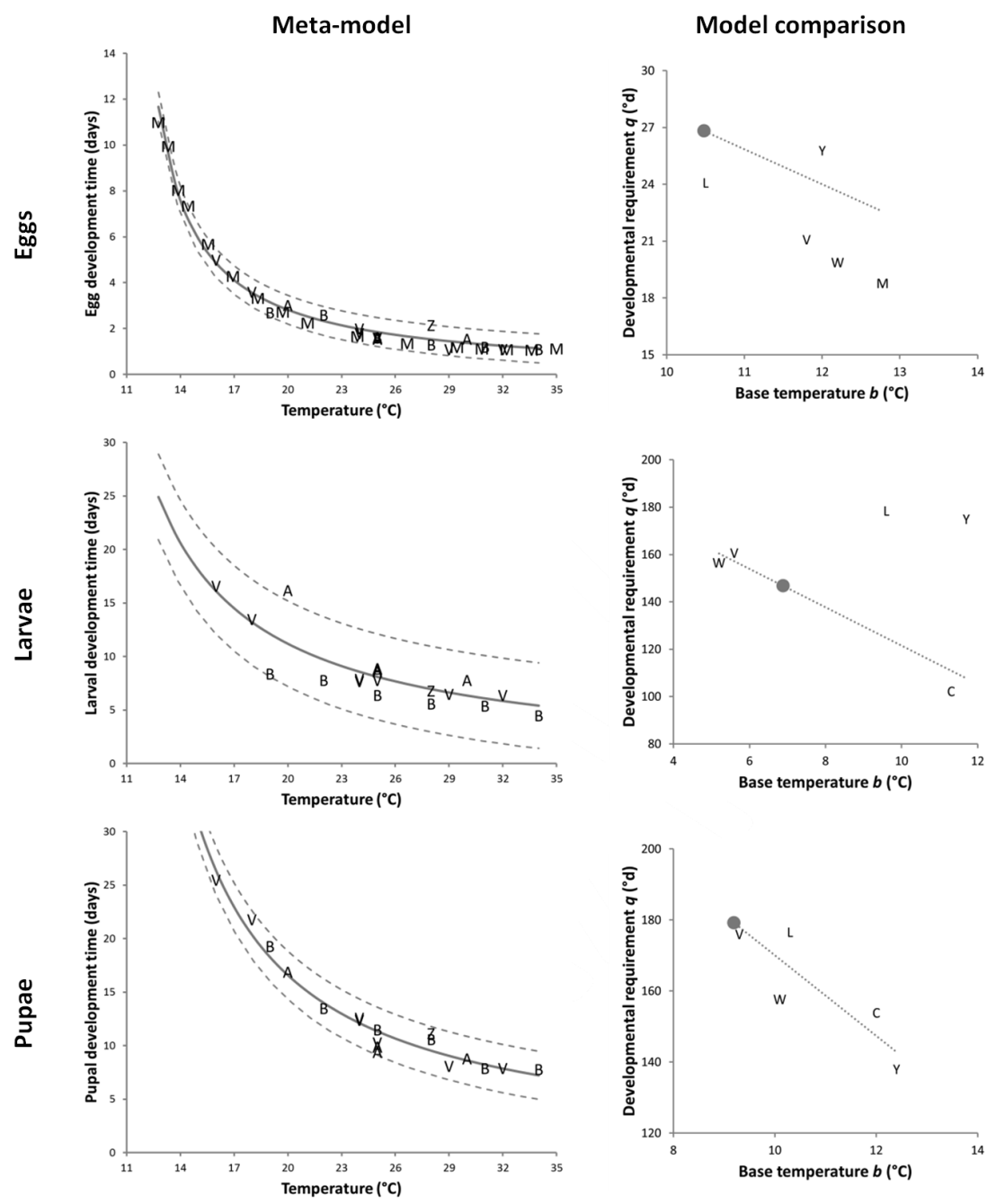

Figure 3 Meta-analysis of development times for oriental fruit fly life stages, as for Figure 2. Data sources: A = Liu et al. (1985); B = Yang et al. (1994); C = Chen et al. (2010); L = Luo et al. (2009); M = Messenger \& Flitters (1958); V = Vargas et al. (1984, 1996, 1997, 2000); W = Wu et al. (2000); Y = Yuan et al. (2005); $Z=$ Zhang et al. (2010).

\section{Validation of voltinism}

Table 1 lists twenty locations where voltinism has been recorded, and Figure 4 shows the observed versus predicted values. Considering all species together $(n=21)$, linear regression of observed versus predicted values (Piñeiro et al. 2008) suggested that the slope of the fitted line did not differ significantly from 1 and the intercept did not differ significantly from 0 , but the root mean squared deviation of 1.7 generations suggests there was considerable error. Thiel's partial inequality coefficients (Smith \& Rose 1995 ) suggested that $85 \%$ of this error was not due to the slope or intercept. Similar results were obtained for the three species analysed separately.

\section{DISCUSSION}

The current paper gives the most comprehensive synthesis and comparison of development times for these three fruit fly species to date. 
Table 1 Observed voltinism of fruit flies at different sites compared with predictions from the metamodels. Predictions assume one generation of Queensland fruit fly requires $602^{\circ} \mathrm{d}$ above $11^{\circ} \mathrm{C}$, Mediterranean fruit fly requires $659^{\circ} \mathrm{d}$ above $8.3^{\circ} \mathrm{C}$, and oriental fruit fly requires $876^{\circ} \mathrm{d}$ above $9.5^{\circ} \mathrm{C}$.

\begin{tabular}{|c|c|c|c|c|c|}
\hline \multirow[b]{2}{*}{ Location, country } & \multirow{2}{*}{$\begin{array}{l}\text { CliMond site } \\
\text { (lat., long.) }\end{array}$} & \multirow{2}{*}{$\begin{array}{c}\text { Estimated } \\
{ }^{\circ} \mathrm{d} / \text { year }\end{array}$} & \multicolumn{2}{|c|}{ Generations per year } & \multirow[b]{2}{*}{ Reference } \\
\hline & & & Predicted & Observed & \\
\hline \multicolumn{6}{|l|}{ Queensland fruit fly } \\
\hline Wilton, AU & $-34.25,150.75$ & 1922 & 3.2 & 4 to 5 & Fletcher (1974) \\
\hline Melbourne, AU & $-37.75,144.92$ & 1565 & 2.6 & 2 to 3 & O'Loughlin et al. (1984) \\
\hline Wodonga, AU & $-36.08,146.92$ & 1826 & 3.0 & 3.7 & \\
\hline Adelaide, AU & $-34.92,138.58$ & 2073 & 3.4 & 3 to 4 & Maelzer (1990) \\
\hline Sydney, AU & $-33.92,151.25$ & 2478 & 4.1 & 3 to 4 & \\
\hline Orange, AU & $-33.25,149.08$ & 1290 & 2.1 & 1 to 2 & Muthuthantri (2008) \\
\hline \multicolumn{6}{|c|}{ Mediterranean fruit fly } \\
\hline Madiera, PT & $32.75,-16.92$ & 2198 & 3.3 & 8 & da Silva Vieira (1952) \\
\hline Honolulu, US & $21.25,-157.75$ & 5495 & 8.3 & 11 to 13 & Hagen et al. (1981) \\
\hline Paris, FR & $48.92,2.42$ & 1573 & 2.4 & 2 & \\
\hline Rome, IT & $41.92,12.42$ & 2769 & 4.2 & 6 to 7 & \\
\hline Santa Clara, US & $37.25,-121.42$ & 2528 & 3.8 & 3 to 3.5 & \\
\hline $\begin{array}{l}\text { coastal high plains, } \\
\text { GT }\end{array}$ & $14.08,-90.92$ & 7068 & 10.7 & 10 to 12 & Eskafi \& Kolbe (1990) \\
\hline $\begin{array}{l}\text { elevations }>2000 \mathrm{~m} \text {, } \\
\text { GT }\end{array}$ & $15.42,-91.08$ & 2836 & 4.3 & $\begin{array}{c}2 \text { in } 5 \\
\text { months }\end{array}$ & \\
\hline Adelaide, AU & $-34.92,138.58$ & 2961 & 4.5 & 4 & Maelzer (1990) \\
\hline southern FR & $43.58,1.42$ & 2191 & 3.3 & 2 & Cayol \& Causse (1993) \\
\hline Thessaloniki, GR & $40.58,22.92$ & 2952 & 4.5 & 4 to 5 & Papadopoulos et al. (2001) \\
\hline Aydin, TR & $37.92,27.92$ & 2546 & 3.9 & 6 to 7 & Karagoz et al. (2009) \\
\hline \multicolumn{6}{|l|}{ oriental fruit fly } \\
\hline Hekou, CN & $22.58,103.92$ & 4917 & 5.6 & 5 & Jiang et al. (2001) \\
\hline Ruili, CN & $24.08,97.92$ & 3655 & 4.2 & 6 & \\
\hline Kunming, CN & $25.08,102.75$ & 2230 & 2.5 & 2 & Ye \& Liu (2005) \\
\hline Wuhan, CN & $30.58,114.25$ & 3204 & 3.7 & 4 to 5 & Han et al. (2011) \\
\hline
\end{tabular}

Previous authors (e.g. Vargas et al. 1996) assessed similarities between development models by comparing the developmental requirements $q$, but this is uninformative when the base temperatures $b$ differ because $q$ depends on $b$. More often, authors compared models in terms of $b$, but without reference to $q$. Here, for the first time, a pivot temperature (Morris \& Fulton 1970) has been used to compare fruit fly development models in terms of both $b$ and $q$, which allowed identification of which models predict relatively longer development times and which shorter. The choice of pivot temperature, $25^{\circ} \mathrm{C}$, matched the typical median temperature used in laboratory studies of fruit flies, but in New Zealand's temperature climate there may be more interest in development times at lower temperatures.
Because of the way they have been fitted, the new models for Medfly and oriental fruit fly should perform better than previous models at the lower end of the suitable temperature range (Kramer et al. 1991).

Some authors (e.g. Tassan et al. 1982) refitted models to development data from other studies, but this is the first time models were fitted to collective data from a range of Medfly and oriental fruit fly studies. This analysis also indicated variability between genotypes, rearing conditions and study methods. For example, conformity between different studies of Medfly or oriental fruit fly egg development times (Figures 2 and 3, top left) suggests higher confidence in the new models. Larval development times were more variable, probably 


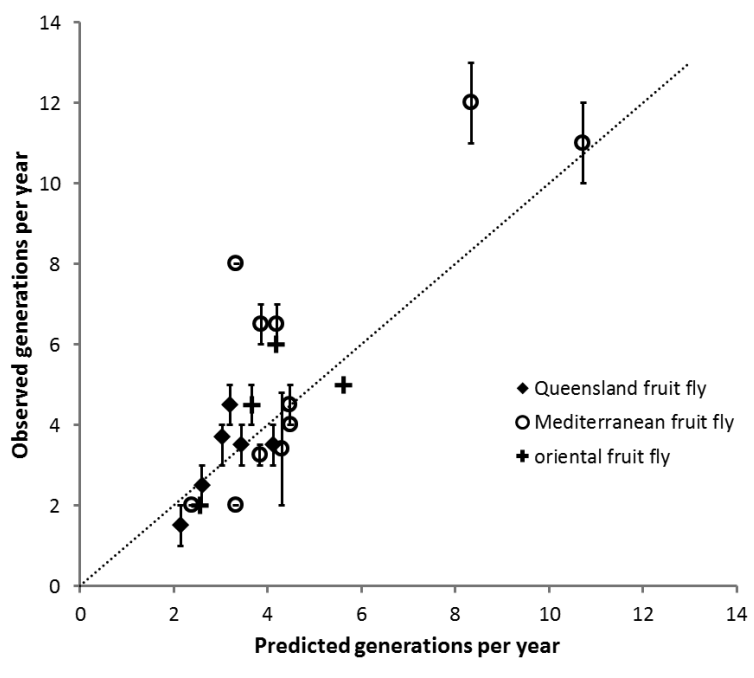

Figure 4 Observed versus predicted voltinism for three fruit fly species (Table 1). Vertical error bars indicate published ranges of generations per year; the diagonal dotted line shows where model fit is perfect.

reflecting differences in host substrate suitability (Carey 1984; Krainacker et al. 1987), but pupal development was more consistent. The greatest uncertainty was associated with the duration of the female pre-oviposition period, which varied widely between studies and between treatments within studies, suggesting that factors other than temperature may influence this life stage.

There is some confusion in the literature about what constitutes "generation time". In some cases the mean egg-to-first-egg time is used, as in the Australian COP for Qfly (Anonymous 1996). This might be considered a minimum generation time, and for the species examined here, that value was considerably shorter than the egg-to-median-egg time that constituted the mean generation time obtained from life table analyses (e.g. Fitt 1990). Validation of the egg-to-median-egg models suggested that they are appropriate, on average, for estimating voltinism in the field although the predictions for some sites were inaccurate. The low precision (i.e. spread around the regression line in Figure 4) might be partly attributed to the temperature data used for validating voltinism being only approximate in time and space.
Insect phenology models are widely and routinely used in pest management and, more recently, in biosecurity management (Nietschke et al. 2007). These models can inform risk analysis by suggesting climate suitability, voltinism and potential impacts in invaded areas (Kean \& Kumarasinghe 2007). For example, Meats (1981) estimated the voltinism of Qfly across Australia and concluded that the low number of generations possible in southern Victoria constrained populations from reaching damaging levels by summer's end, and speculated that Qfly would only cause significant damage in areas that can sustain at least three generations per year. In New Zealand, temperatures suggest that this would only be the case from the Hauraki Plains north (J.M. Kean, unpublished data). Potential voltinism has also been used as an index of climate suitability in more complex assessments of spatial and temporal biosecurity risk (Magarey et al. 2011).

Other uses for phenology models in biosecurity include trace-back (assessing the potential circumstances of introduction) and trace-forward (forecasting subsequent growth and spread), both of which may be important aspects of incursion responses (van Havre \& Whittle 2015). A development model run on local temperatures may suggest when an insect invader arrived, and which life stages should be targeted by surveillance. For example, international guidelines for proving area freedom from fruit flies recommend that surveillance should be maintained for up to three generation times after the last confirmed detection (FAO 2006), whereas the Australian COP for Qfly uses one generation (calculated as the egg-to-first-egg generation time) plus 28 days (Anonymous 1996). The development models derived here were used to estimate these dates for the current Qfly incursion in Auckland (J.M. Kean, unpublished data).

\section{ACKNOWLEDGEMENTS}

I am grateful to Dave Voice (MPI) for useful discussion, and to Craig Phillips, Alison Popay, Sue Zydenbos and an anonymous reviewer for helpful feedback on the manuscript. This work was funded by the Ministry for Primary Industries 
RFP 15184 and by AgResearch's contribution to the Better Border Biosecurity (B3) cooperative research programme (b3nz.org).

\section{REFERENCES}

Acosta H, White P 2011. Atlas of Biosecurity Surveillance, 2011 May. Ministry of Agriculture and Forestry, Wellington, New Zealand.

Anonymous 1996. Code of practice for management of Queensland fruit fly. Standing Committee on Agriculture and Resource Management, Department of Primary Industries, Canberra, Australia.

Bodenheimer FS 1951. Citrus Entomology in the Middle East. W. Junk, The Hague, Netherlands. 663 pp.

Brown AM 2001. A step-by step guide to nonlinear regression analysis of experimental data using a Microsoft Excel spreadsheet. Computer Methods and Programs in Biomedicine 65: 191-200.

Carey JR 1984. Host-specific demographic studies of the Mediterranean fruit fly Ceratitis capitata. Ecological Entomology 9: 261-270.

Cayol JP, Causse R 1993. Mediterranean fruit fly Ceratitis capitata Wiedemann (Dipt., Trypetidae) back in Southern France. Journal of Applied Entomology 116: 94-100.

Chen L, Zhu C, Xia X 2010. A preliminary study on the biological characters of Bactrocera dorsalis (Hendel) in Shanghai area. Acta Agriculturae Shanghai 26: 99-101.

Crovetti A, Conti B, Delrio G 1986. Effect of abiotic factors on Ceratitis capitata (Weid.) (Diptera: Tephritidae) II. Pupal development under constant temperatures. In: Cavalloro $\mathrm{CV}$ ed. Fruit Flies of Economic Importance. A.A. Balkema Publishers, Rotterdam, The Netherlands. Pp. 141-148.

da Silva Vieira RM 1952. A Mosca da Fruta (Ceratitis capitata (Wied.)) na Ilha da Madeira. Edição do Grémio dos Exportadores de Frutas e Produtos Hortícolas da Ilha da Madeira, Madiera, Portugal.

de Lima CPF 2008. Area wide management of Mediterranean fruit fly in Australia. Acta Horticulturae 803: 51-60.
Delrio G, Conti B, Crovetti A 1986. Effect of abiotic factors on Ceratitis capitata (Weid.) (Diptera: Tephritidae) I. Egg development under constant temperatures. In: Cavalloro $\mathrm{CV}$ ed. Fruit Flies of Economic Importance. A.A. Balkema Publishers, Rotterdam, The Netherlands. Pp. 133-140.

Duyck PF, Quilici S 2002. Survival and development of different life stages of three Ceratitis spp. (Diptera: Tephritidae) reared at five constant temperatures. Bulletin of Entomological Research 92: 461-469.

Eskafi FM, Kolbe ME 1990. Infestation patterns of commonly cultivated edible fruit species by Ceratitis capitata and Anastrepha spp. (Diptera: Tephritidae) in Guatemala and their relationship to environmental factors. Environmental Entomology 19: 1371-1380.

FAO 2006. International standards for phytosanitary measures ISPM 26: Establishment of pest-free areas for fruit flies (Tephritidae). Secretariat of the International Plant Protection Convention, Food and Agriculture Organization of the United Nations.

Fitt GP 1990. Comparative fecundity, clutch size, ovariole number and egg size of Dacus tryoni and D. jarvisi, and their relationship to body size. Entomologia Experimentalis et Applicata 55: 11-21.

Fletcher BS 1974. The ecology of a natural population of the Queensland fruit fly, Dacus tryoni. VI. Seasonal changes in fruit fly numbers in the areas surrounding the orchard. Australian Journal of Zoology 22: 353-363.

Grout TG, Stoltz KC 2007. Developmental rates at constant temperatures of three economically important Ceratitis spp. (Diptera: Tephritidae) from Southern Africa. Environmental Entomology 36: 1310-1317.

Hagen KS, Allen WW, Tassan RL 1981. Mediterranean fruit fly: The worst may be yet to come. California Agriculture 35: 5-7.

Han P, Wang X, Niu C-Y, Dong Y-C, Zhu J-Q, Desneux N 2011. Population dynamics, phenology, and overwintering of Bactrocera dorsalis (Diptera: Tephritidae) in Hubei Province, China. Journal of Pest Science 84: 289-295. 
Jiang X-L, He W-Z, Xiao S, Ren L-Q, Sun B-Z, Zhang C-L 2001. Study on the biology and survival of Bactrocera dorsalis in the border region of Yunnan. Journal of Southwest Agricultural University 2001.

Karagoz M, Gulcu B, Hazir C, Kaya HK, Hazir S 2009. Biological control potential of Turkish entomopathogenic nematodes against the Mediterranean fruit fly Ceratitis capitata. Phytoparasitica 37: 153-159.

Kean JM 2013. How accurate are methods for predicting phenology in New Zealand? New Zealand Plant Protection 66: 124-131.

Kean JM, Kumarasinghe L 2007. Predicting the seasonal phenology of fall webworm (Hyphantria cunea) in New Zealand. New Zealand Plant Protection 60: 279-285.

Krainacker DA, Carey JR, Vargas RI 1987. Effect of larval host on life history traits of the Mediterranean fruit fly, Ceratitis capitata. Oecologia 73: 583-590.

Kramer DA, Stinner RE, Hain FP 1991. Time versus rate in parameter estimation of nonlinear temperature-dependent development models. Environmental Entomology 20: 484-488.

Kriticos DJ, Webber BL, Leriche A, Ota N, Macadam I, Bathols J, Scott JK 2012. CliMond: global high-resolution historical and future scenario climate surfaces for bioclimatic modelling. Methods in Ecology and Evolution 3: 53-64.

Liu Y-C, Chi H, Chen S-H 1985. Influence of temperature and food on the population parameters of oriental fruit fly, Dacus dorsalis Hendel (Diptera: Tephritidae). Chinese Journal of Entomology 5: 1-10.

Luo Z-X, Ren L-L, Qi L-Y, Zhou S-D, Dai H-G 2009. Effects of temperature on the development of Bactrocera dorsalis (Diptera:Tephritidae) populations. Chinese Journal of Ecology 2009.

Maelzer DA 1990. Fruit-fly outbreaks in Adelaide, S.A., from $1948-49$ to $1985-86$. II. The phenology of both pestilent species. Australian Journal of Zoology 38: 555-572.

Magarey RD, Borchert DM, Engle JS, ColungaGarcia M, Koch FH, Yemshanov D 2011. Risk maps for targeting exotic plant pest detection programs in the United States. EPPO Bulletin 41: 46-56.
Meats A 1981. The bioclimatic potential of the Queensland fruit fly, Dacus tryoni, in Australia. Proceedings of the Ecological Society of Australia 11: 151-161.

Messenger PS, Flitters NE 1958. Effect of constant temperature environments on the egg stage of three species of Hawaiian fruit flies. Annals of the Entomological Society of America 51: 109-119.

Morris RF, Fulton WC 1970. Models for the development and survival of Hyphantria cunea in relation to temperature and humidity. Memoirs of the Entomological Society of Canada 70: 1-60.

Muñiz M, Zalom FG 1997. Developmental rate and number of generation estimates for Ceratitis capitata (Wiedemann) in fruit growing regions of California. IOBC/WPRS Bulletin 20: 55-66.

Muthuthantri S 2008. Population phenology of the tropical fruit fly, Bactrocera tryoni (Froggatt) (Diptera: Tephritidae), in Queensland, Australia. Masters thesis, Queensland University of Technology, Australia.

Nietschke BS, Magarey RD, Borchert DM, Calvin DD, Jones E 2007. A developmental database to support insect phenology models. Crop Protection 26: 1444-1448.

O'Loughlin GT, East RA, Meats A 1984. Survival, development rates and generation times of the Queensland fruit fly, Dacus tryoni, in a marginally favourable climate: Experiments in Victoria. Australian Journal of Zoology 32: 353-361.

Papadopoulos NT, Katsoyannos BI, Carey JR 2002. Demographic parameters of the Mediterranean fruit fly (Diptera: Tephritidae) reared in apples. Annals of the Entomological Society of America 95: 564-569.

Papadopoulos NT, Katsoyannos BI, Carey JR, Kouloussis NA 2001. Seasonal and annual occurrence of the Mediterranean fruit fly (Diptera: Tephritidae) in northern Greece. Annals of the Entomological Society of America 94: 41-50.

Piñeiro G, Perelman S, Guerschman JP, Paruelo JM 2008. How to evaluate models: Observed vs. predicted or predicted vs. observed? Ecological Modelling 216: 316-322. 
Pritchard G 1970. The ecology of a natural population of Queensland fruit fly, Dacus tryoni III. The maturation of female flies in relation to temperature. Australian Journal of Zoology 18: 77.

Pritchard G 1978. The estimation of natality in a fruit-infesting insect (Diptera: Tephritidae). Canadian Journal of Zoology 56: 75-79.

Quesada-Moraga E, Valverde-García P, GarridoJurado I 2012. The effect of temperature and soil moisture on the development of the preimaginal Mediterranean fruit fly (Diptera: Tephritidae). Environmental Entomology 41: 966-970.

Ricalde MP, Nava DE, Loeck AE, Donatti MG 2012. Temperature-dependent development and survival of Brazilian populations of the Mediterranean fruit fly, Ceratitis capitata, from tropical, subtropical and temperate regions. Journal of Insect Science 12: 1-11.

Shoukry A, Hafez M 1979. Studies on the biology of the Mediterranean fruit fly Ceratitis capitata. Entomologia Experimentalis et Applicata 26: 33-39.

Smith EP, Rose KA 1995. Model goodness-offit analysis using regression and related techniques. Ecological Modelling 77: 49-64.

Tassan RL, Hagen A, Cheng T, Palmer K, Feliciano G, Bough TL 1982. Mediterranean fruit fly life cycle estimations for the California eradication program. In: Cavalloro R ed. Fruit Flies of Economic Importance. Balkema, Athens, Greece. Pp. 564-570.

van Havre Z, Whittle P 2015. Designing surveillance for emergency response. In: Jarrad FC, Low-Choy SJ, Mengersen K ed. Biosecurity Surveillance: Quantitative Approaches. CAB International, Wallingford, Oxfordshire, U.K. Pp. 123-133.

Vargas RI, Miyashita D, Nishida T 1984. Life history and demographic parameters of three laboratory-reared tephritids (Diptera: Tephritidae). Annals of the Entomological Society of America 77: 651-656.

Vargas RI, Walsh WA, Jang EB, Armstrong JW, Kanehisa DT 1996. Survival and development of immature stages of four Hawaiian fruit flies
(Diptera: Tephritidae) reared at five constant temperatures. Annals of the Entomological Society of America 89: 64-69.

Vargas RI, Walsh WA, Kanehisa D, Jang EB, Armstrong JW 1997. Demography of four Hawaiian fruit flies (Diptera: Tephritidae) reared at five constant temperatures. Annals of the Entomological Society of America 90: 162-168.

Vargas RI, Walsh WA, Kanehisa D, Stark JD, Nishida T 2000. Comparative demography of three Hawaiian fruit flies (Diptera: Tephritidae) at alternating temperatures. Annals of the Entomological Society of America 93: 75-81.

Wu J, Liang F, Liang G 2000. Study on the relation between developmental rate of oriental fruit fly and its ambient temperature. Plant Quarantine 2000: 321-324.

Yang P, Carey JR, Dowell RV 1994. Temperature influences on the development and demography of Bactrocera dorsalis (Diptera: Tephritidae) in China. Environmental Entomology 23: 971-974.

Ye H, Liu J-H 2005. Population dynamics of the oriental fruit fly, Bactrocera dorsalis (Diptera: Tephritidae) in the Kunming area, southwestern China. Insect Science 12: 387392.

Yonow T, Zalucki MP, Sutherst RW, Dominiak BC, Maywald GF, Maelzer DA, Kriticos DJ 2004. Modelling the population dynamics of the Queensland fruit fly, Bactrocera (Dacus) tryoni: a cohort-based approach incorporating the effects of weather. Ecological Modelling 173: 9-30.

Yuan S-Y, Kong Q, Xiao C, Chen B, Li Z-Y, Gao Y-H 2005. Developmental threshold temperature and effective cumulative temperature of Bactrocera dorsalis Hendel. Journal of Southwest Agricultural University 2005: 316-318.

Zhang Y, Lu Y, Zeng L, Liang G 2010. Lifehistory traits and population relative fitness of trichlorphon-resistant and -susceptible Bactrocera dorsalis (Diptera: Tephritidae). Psyche 2010: 895935. 